\title{
Investigation of Structure, Microstructure and Magnetic Properties of Nano-Crystalline Zn Ferrite Synthesized at High Temperature
}

\author{
H.H. Hantour, N. Makram. \\ Physics Department, Faculty of Science, Girls, Al-Azhar University, \\ Cairo, Egypt
}

Zinc ferrite nano-material was prepared by direct fusion of $\mathrm{ZnO}$ with $\mathrm{Fe}$ in air. The morphological and structural properties of the system under study were investigated by scanning electron microscope (SEM) and X-ray powder diffraction (XRD) applying MAUD and Win-Fit programs. The X-ray studies show the coexistence of two phases. The major phase (66.66\%) was determined to be the cubic spinel phase of $\mathrm{ZnFe}_{2} \mathrm{O}_{4}$ with average apparent crystallite size of about $48.7 \mathrm{~nm}$ and $81.5 \mathrm{~nm}$ respectively for $\mathscr{D}_{\beta}$ and $\mathscr{D}_{F}$, while the minor phase of $\mathrm{ZnO}$ (33.33\%) has hexagonal structure. The studied zinc ferrite present a uniform microstructure in the form of spherical grains as given by SEM. The type and density of defects as determined by electron spin resonance (ESR) are free spins with density $3.92 \times 10^{23} \mathrm{~cm}^{-3}$. The presence of the $\mathrm{ZnO}$ phase may enhance the creation of Zn vacancies as surface defects that give rise to free spins. The magnetic properties of the system were studied using a vibrating sample magnetometer (VSM) at room temperature under a maximum field of $20 \mathrm{KOe}$. The coerricivity $\left(H_{C}\right)$, approximate saturation magnetization $\left(M_{s}\right)$, remnant magnetization $\left(M_{r}\right)$ and Curie temperature $\left(T_{C}\right)$ are determined. The low value of $M_{s}$ is attributed to the high value of annealing temperature that allowed the formation of a better degree of crystallinity, $i$. e. smaller degree of inversion which enhances the magnetization. Also the absence of magnetic saturation at 20 KOe seems to be due to the effect of both the surface spin disorder in nano regime and the magnetic moment bearing $\mathrm{ZnO}$ impurity phase. The present magnetic investigations argue a ferrimagnetic character of the system under study.

\section{Introduction}

Transition metal ferrites are magnetic materials with cubic spinel structure which have been extensively used in various technological applications such as electronic ignition systems, generators, vending machines, medical implants, wrist watches, inductor core, transformer circuits, magnetic sensors and recording equipment, telecommunications, magnetic fluids, microwave absorbers and other high frequency applications ${ }^{(1-6)}$. In addition, ferrites are much cheaper than most of other magnetic materials, and their magnetic and mechanical properties can be "tailor made" per the requirement of application ${ }^{(7-9)}$. The spinel crystal structure is an approximately close packed face-centered cubic array of anions with holes partly filled by the cations. The oxide spinel can generally be described by the formula $(A)\left[B_{2}\right] \mathrm{O}_{4}$, where $\mathrm{A}$ and $\mathrm{B}$ denote divalent and trivalent cations, respectively. In the case of a normal spinel structure, all of the $A$ atoms are tetrahedrally coordinated while the $\mathrm{B}$ atoms are octahedrally coordinated by oxygen atoms. In the case of an inverse spinel structure, the A atoms occupy half of the B sites ${ }^{(10)}$. 
Among the spinel ferrite, zinc ferrites have been one of the most widely studied systems due to their intriguing magnetic and catalytic properties and also due to their enhanced chemical reactivity, which makes them ideal candidates for many technological applications such as magnetic materials ${ }^{(11,12)}$, gas sensors $^{(13)}$, catalysts $^{(14)}$, photocatalysts ${ }^{(15)}$ and absorbent materials ${ }^{(16)}$.

The properties of ferrite materials are strongly influenced by the materials' composition and microstructure, which are sensitive to the preparation methodology used in their synthesis ${ }^{(17)}$. In addition, the sintering conditions employed and the impurity levels present in or added to these materials also change their properties ${ }^{(18)}$. The selection of an appropriate process is, therefore, the key to obtain good quality ferrites. In this paper the system under study was synthesized by direct fusion method. Investigation of structural and microstructural properties of the prepared system through X-ray diffraction (XRD) and scanning electron microscope (SEM) is given. The electron spin resonance (ESR) technique was used to detect the density and the type of free spins that affecting the spinel ferrite. Finally, studies of the magnetic properties under the variation of both the applied magnetic field and temperature are also given.

\section{Experimental}

The Zinc ferrite was prepared by direct fusion of $\mathrm{ZnO}(99.97 \%)$ with Fe (99.999\%). Firstly, the mixture was hand milled in an agate mortar for $5 \mathrm{~h}$. The resultant powder was subsequently annealed in air at $1000 \mathrm{C}^{\circ}$ for $2 \mathrm{~h}$ then the temperature was allowed to decrease to $700 \mathrm{C}^{\circ}$. The later was kept constant for 15 days. In order to investigate the structural and the microstructure, the system under study is subjected to X-ray diffraction analysis using $\mathrm{Cu} \mathrm{K}_{\alpha}$ radiation. The X-ray diffractometr used is a Philips X' pert MPP diffractometr with a goniometer type PW3050/10. To reduce preferred orientation the following two steps were considered: first, the material was reduced to a fine state by grinding in agate mortar, this step also reduces the errors arising from the micro absorption effects. Second, back-loading was used for packing the samples. SEM (Model JEOL, Japan) was used to investigate the surface morphology of the sample. The magnetic properties were measured using LakeShore 7410 vibrating sample magnetometer (VSM) model at room temperature under a maximum field of $20 \mathrm{kOe}$. In this work, Faraday's method is used to measure the magnetic susceptibility at different temperatures as a function of the magnetic field intensity. This technique is used to detect the Curie temperature $T_{C}$ and the effective magnetic moment of the system under study. The ESR was studied using Bruker EMX spectrometer (x-bandGermany product model).

\section{Results and discussion}

\subsection{Structural and microstructral analysis}

Structural studies means to detect the locations of the atoms in the unit cell while microstructural means to find the crystallite size, strain and type of defects. Fig. 1 shows the x-ray diffraction pattern of the system under study.

Applying the search match program, it was found that the phase spinel structure of $\mathrm{ZnFe}_{2} \mathrm{O}_{4}$ is formed. Zinc oxide as a second phase was detected in the X-ray pattern of Fig.1. The major phase of $\mathrm{ZnFe}_{2} \mathrm{O}_{4}$ as calculated by MAUD program forms $66.66 \%( \pm 0.0463)$ the $\mathrm{Zn}$ ferrite under study. The specific ICDD card number (82-1042) shows cubic structure with space group Fd-3m and lattice parameter $\mathrm{a}=8.44256 \AA$. The minor phase of $\mathrm{ZnO}$ $(33.33 \%)$ was identified using the ICDD card number (36-1451) which gives hexagonal structure with space group $\mathrm{P} 63 \mathrm{mc}$ and lattice parameters $\mathrm{a}=$ 
$3.25089 \AA$ and $\mathrm{c}=5.2079 \AA$. Good reliability factors for $\mathrm{R}_{\mathrm{wp}} \%=11$ and $\mathrm{R}_{\mathrm{b}} \%=$ 7.3 were calcuated. It will be shown through the study of the magnetic properties that the presence of the $\mathrm{ZnO}$ phase together with the main phase of

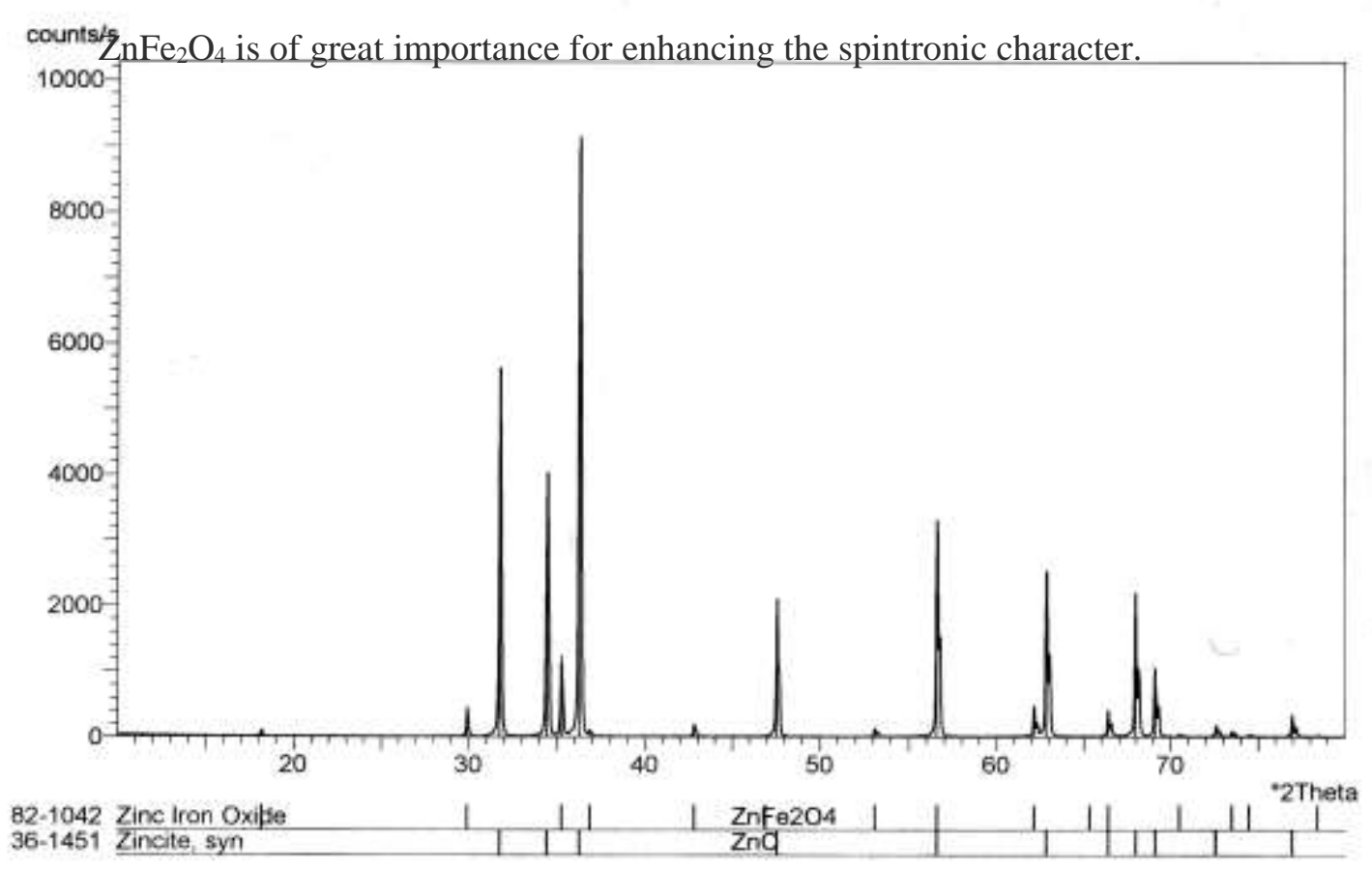

Fig.1. The diffraction pattern of the $\mathrm{Zn}$ ferrite system under study.

Fig.2 shows the profile fitting of the system under study while table.1 gives the refined structural parameters obtained from Rietveld refinement applying the program MAUD ${ }^{(19)}$. The usual sequence of parameters refinement are: the scale factor, the zero shift and background parameters, the lattice parameters, peak profile parameters (size and strain), the atoms position and occupancy and finally the displacement parameters.

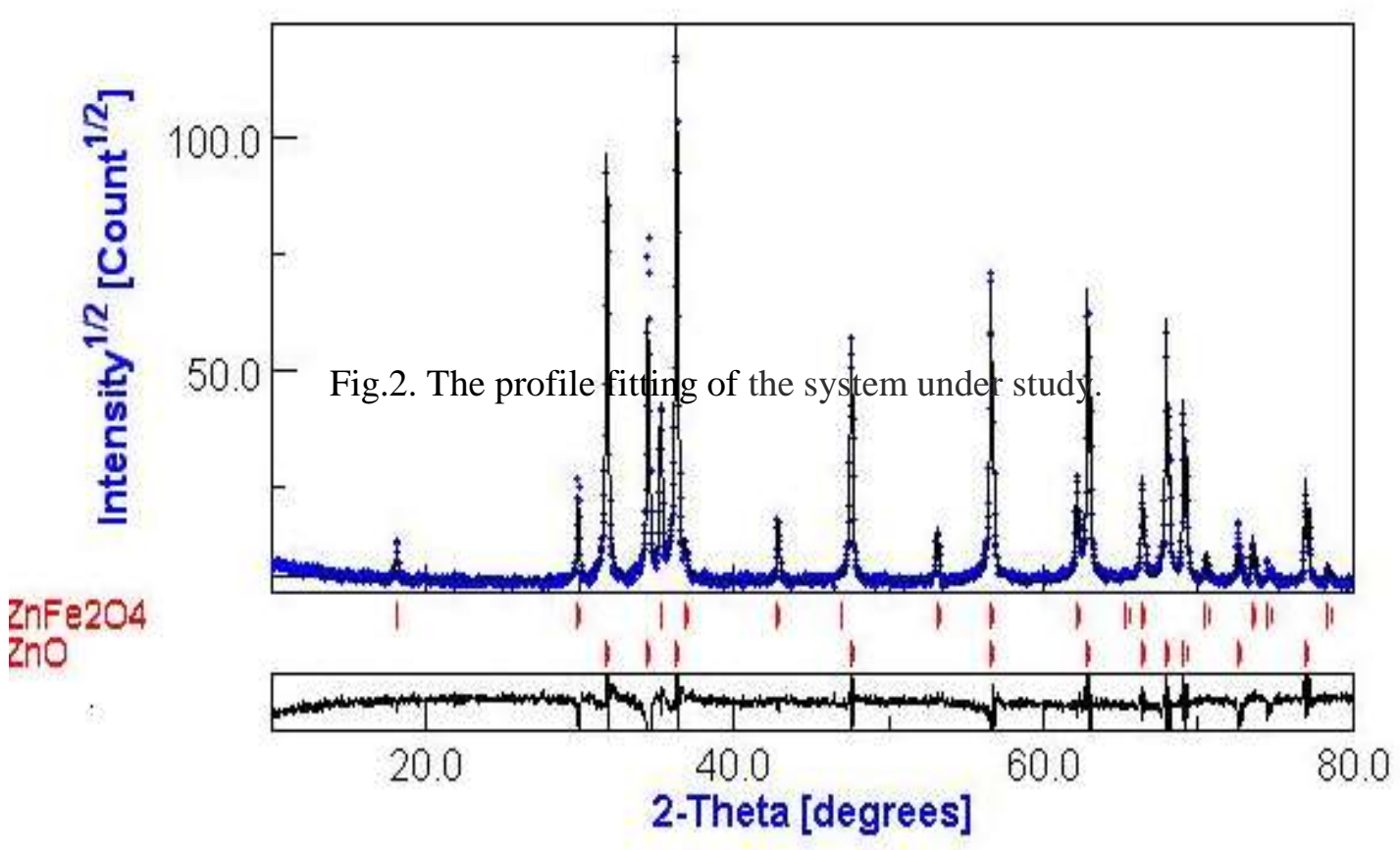


Table.1. The refined lattice parameters $\mathrm{a}(\AA)$ and $\mathrm{c}(\AA)$ and the reliability factors:

$\mathrm{R}_{\mathrm{wp}} \%$ and $\mathrm{R}_{\mathrm{p}} \%$ obtained from Rietveld analysis of the powder XRD patterns for the system under study.

\begin{tabular}{|lcc|}
\hline & $\mathrm{ZnFe}_{2} \mathrm{O}_{4}$ & $\mathrm{ZnO}$ \\
\hline $\mathrm{a}(\AA)$ & 8.44256 & 3.25089 \\
$\mathrm{c}(\AA)$ & - & 5.2079 \\
Phase\% & $66.66 \%$ & $33.33 \%$ \\
$\mathrm{R}_{\mathrm{wp}} \%$ & 11 & 11 \\
$\mathrm{R}_{\mathrm{p}} \%$ & 7.3 & 7.3 \\
\hline
\end{tabular}

Applying the win-fit program, the resulting apparent crystallite size $\mathscr{D}_{\beta}(\mathrm{nm}) \& \mathscr{D}_{\mathrm{F}}(\mathrm{nm})$ and root mean square strain $\left\langle\boldsymbol{e}_{\mathrm{g}}\right\rangle$ from single and multiple line analysis are given in table 2 .

Table 2. Apparent crystallite size $\mathscr{D}_{\beta}(\mathrm{nm}) \& \mathscr{D}_{\mathrm{F}}(\mathrm{nm})$ and root mean-square strain $\left\langle e_{g}\right\rangle$ from single and multiple line analysis of the sample

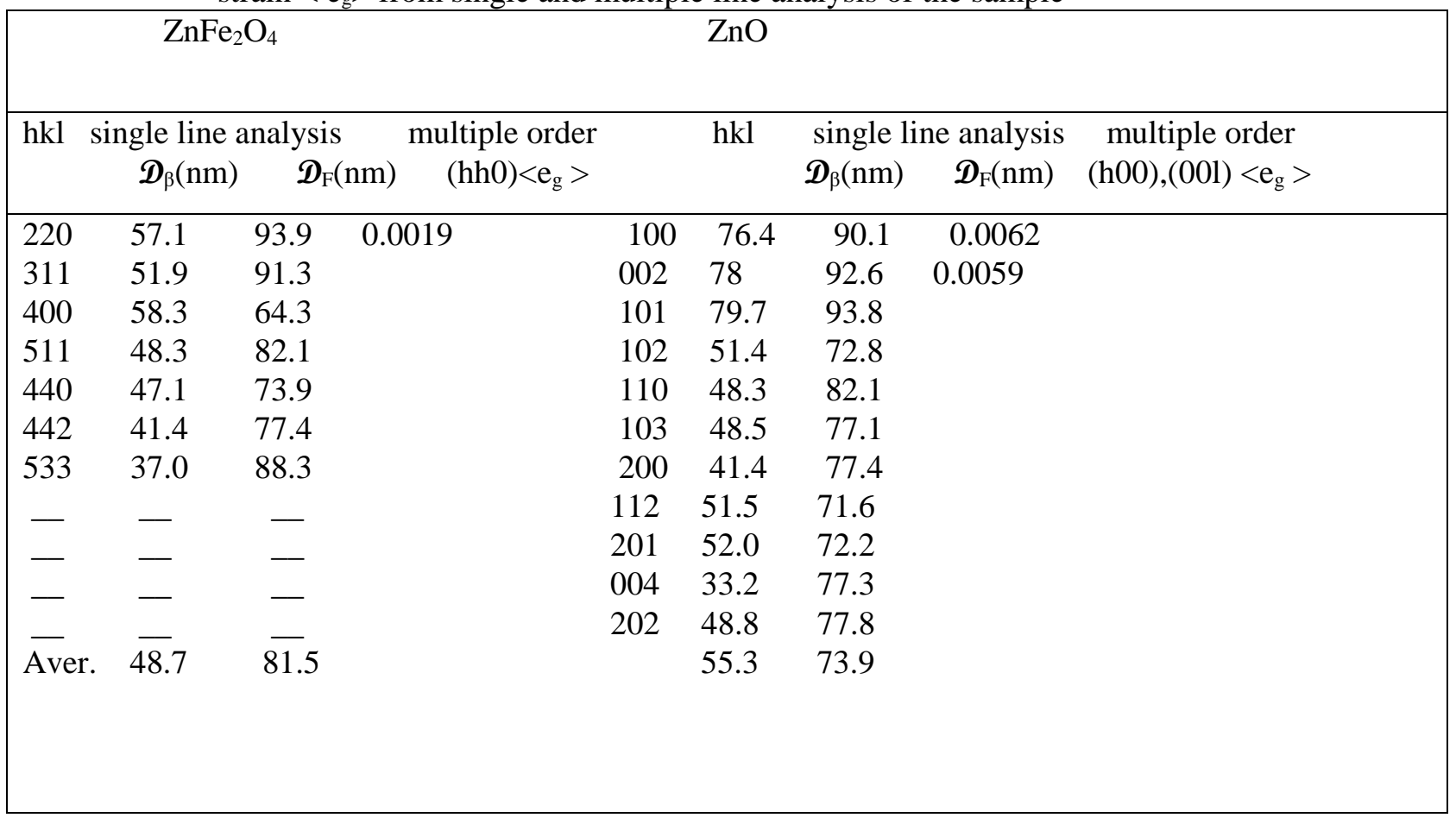

Fig. 3 displays the scanning electron microscope images taken at different magnifications for the system under study. As shown, nice agglomerations of spherically shaped grains of approximately equal sizes tacke place. Comparing with the crystallite size calculated through the x-ray data given in table. 2 , it is obvious that each grain is composed of many nano crystallites.
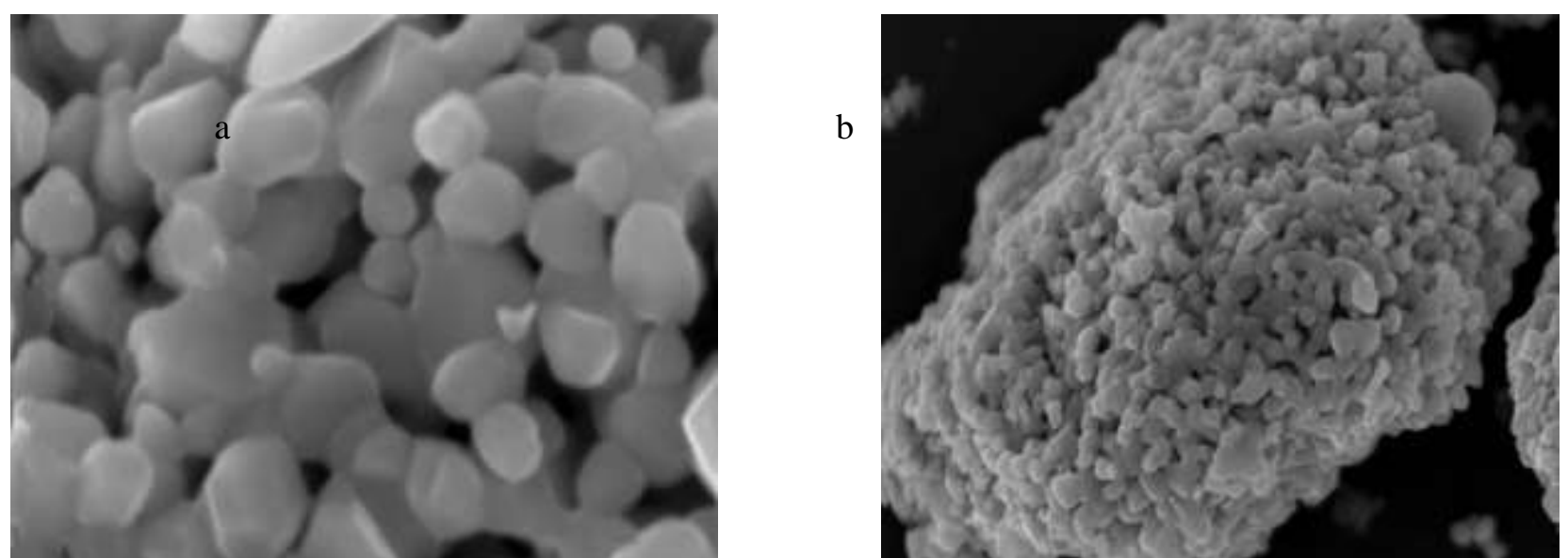
Fig.3(a,b). SEM micrographs of the system under study at different magnifications.

\subsection{Electron Spin Resonance studies:}

Experimental ESR signal detected for the system under study is displayed in Fig.4. The spectrum takes the form of a broad line. The calculated values of the width $(\Delta \mathrm{H})$, the $g$ factor and the density of free spin $\left(\mathrm{N}_{\mathrm{s}}\right)$ are given in table 3. According to the g value, it is clear that the absorption signal of the ESR arises due to the presence of free electrons as defect centers. The presence of the $\mathrm{ZnO}$ phase detected through XRD studies (table 1) may enhance the creation of broken bonds since nano-crystalline $\mathrm{ZnO}$ is known to form $\mathrm{Zn}$ vacancies as surface defects.

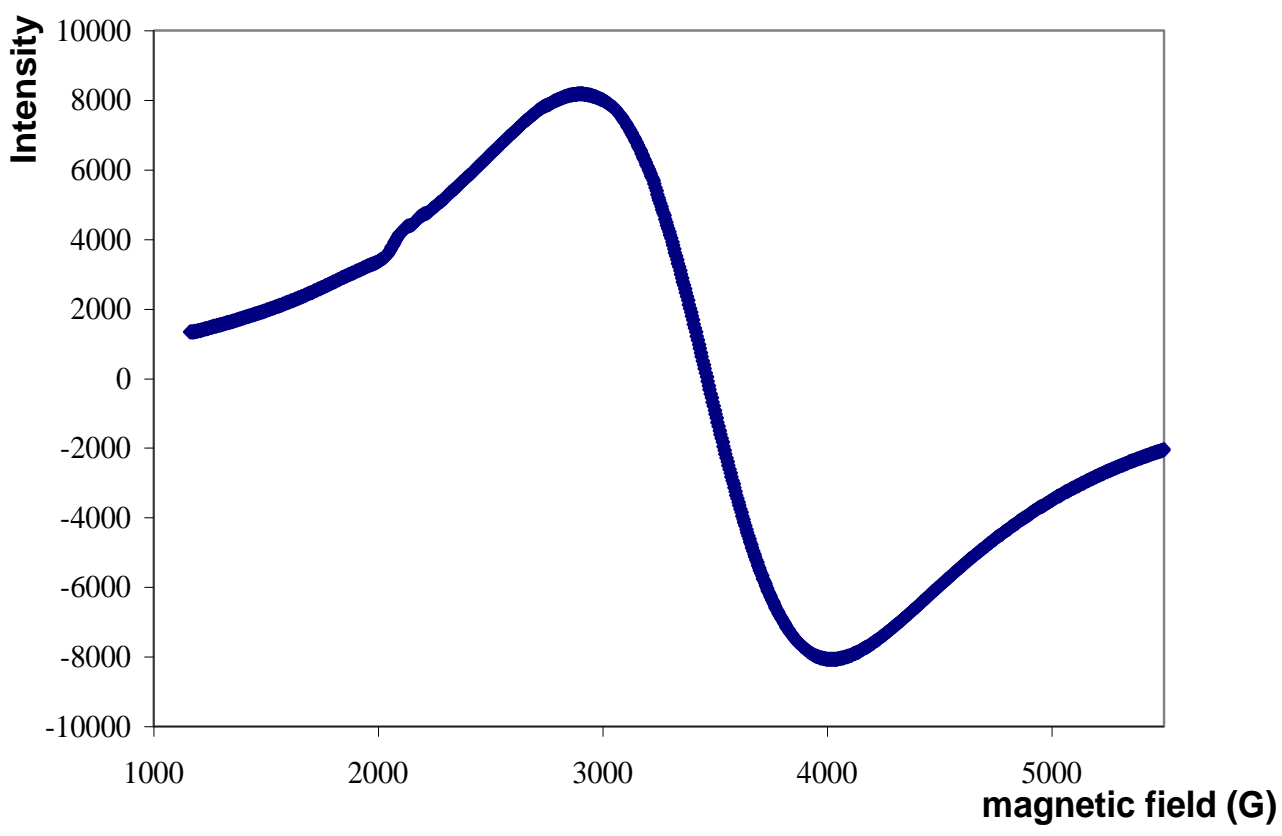

Fig.4. Electron Spin Resonance of the system under study.

Table 3. Values of $\Delta \mathrm{H}, \mathrm{g}$ factor and $\mathrm{N}_{\mathrm{s}}$ of the system under study.

\begin{tabular}{|c|c|c|}
\hline$\Delta \mathrm{H}(\mathrm{G})$ & $\mathrm{g}$ & $\mathrm{N}_{\mathrm{s}} \mathrm{cm}^{-3}$ \\
\hline 915.74 & 2.00424 & $3.92 \times 10^{23}$ \\
\hline
\end{tabular}

\subsection{Magnetization and hystersis loop studies:}

The hysteresis behavior in nano $\mathrm{ZnFe}_{2} \mathrm{O}_{4}$ compared to its bulk counterpart can be raised due to two main mechanisms: the first is the redistribution of cations between tetrahedral and octahedral sites while the second is the spin canting component between tetrahedral and octahedral sites.

Bulk $\mathrm{ZnFe}_{2} \mathrm{O}_{4}$ is a normal spinel where $\mathrm{Zn}$ ions occupy A-site and $\mathrm{Fe}$ ions strictly occupy B sites. Since non magnetic Zn ions occupy the A-site, the resultant magnetic moment is largely due to weak antiferromagnetic exchange interactions between magnetic $\mathrm{Fe}-\mathrm{Fe}$ ions in the $\mathrm{B}$-site. Therefore, bulk $\mathrm{ZnFe}_{2} \mathrm{O}_{4}$ possesses near zero moment at room temperature. Concerning the nano case, recent studies for sol-gel prepared nano $\mathrm{ZnFe}_{2} \mathrm{O}_{4}$ by XRD and FTIR show that the $\mathrm{Fe}^{3+}$ ions are found to occupy both $\mathrm{A}$ - and $\mathrm{B}$-sites ${ }^{(20)}$. Such inversion was also recorded for $\mathrm{ZnFe}_{2} \mathrm{O}_{4}$ prepared via different synthesis processes such as hydrothermal synthesis ${ }^{(21)}$, thermal plasma synthesis ${ }^{(2)}$, high 
energy ball milling( ${ }^{(23)}$, molecular beam epitaxy ${ }^{(24)}$, pulsed laser deposition ${ }^{(25)}$ and solid state reaction ${ }^{(26)}$. Further evidences for the presence of $\mathrm{Zn}^{2+}$ in B-site and $\mathrm{Fe}^{3+}$ in A-site has been reported by Jeyadevan et al. ${ }^{(27)}$ and by Misra et al. ${ }^{(28)}$ through extended X-ray absorption fine structure studies and by Lotgering ${ }^{(29)}$ through neutron diffraction studies.

According to the $\mathrm{M}(\mathrm{H})$ relation given in Fig.5, a very thin hysteresis loop with high value of coerricivity of about $289 \mathrm{G}$ was obtained. An estimated value of approximately $0.37607 \mathrm{emu} / \mathrm{g}$ was determined for the saturation magnetization. A very small value of $0.006762 \mathrm{emu} / \mathrm{g}$ was also obtained for the remanent magnetization. The overall magnetic behavior given in Fig.5 can be well accounted for in terms of an exchange interaction occurring as a result of cation redistribution. Therefore, $\mathrm{Fe}-\mathrm{Fe}$ interaction between $\mathrm{A}-\mathrm{B}$ sublattices dominates and is much stronger than $\mathrm{Fe}-\mathrm{Fe}$ ions interaction in the $\mathrm{B}$ site. A ferrimagnetic or uncompensated moment arises from this $\mathrm{A}-\mathrm{B}$ exchange interaction due to the unequal number of $\mathrm{Fe}^{3+}$ ions in the two types of sites. Thus the exchange effect between $\mathrm{Fe}^{3+}$ ions in both the sites is accountable for the observation of hysteresis loop at room temperature as shown in Fig.5. The ferrimagnetic behavior of nano Zn-ferrite has been observed by Mozaffari et $\mathrm{al}^{(30)}$, Chinnasamy et al. ${ }^{(31-32)}$, Jun Wang et al. ${ }^{(33)}$ and Oliver et al. ${ }^{(34)}$. In fact, the $\mathrm{ZnFe}_{2} \mathrm{O}_{4}$ under study was prepared through solid state reaction by annealing in air at relatively high temperature up to $1000 \mathrm{C}^{\circ}$. Then the temperature was allowed to decrease to $700 C^{\circ}$ where it kept constant for 15 days. Such high temperature enhances the formation of a better degree of crystallinity (sharp diffraction lines, Fig.1) and large crystallite size (table.2). It seems that the degree of inversion that enhances the magnetization decreases as the crystallite size increases; in other words as the annealing temperature $\left(\mathrm{T}_{\mathrm{A}}\right)$ increases. Mozaffari et $\mathrm{al}^{(30)}$ have reported that the ionic distribution of the Ze ferrite nanoparticles tends to that of the bulk by increasing $\left(\mathrm{T}_{\mathrm{A}}\right)$. Their results show that the $\mathrm{M}-\mathrm{H}$ relation changes from the $\mathrm{S}$ shape to a nearly linear shape by increasing $\mathrm{T}_{\mathrm{A}}$.

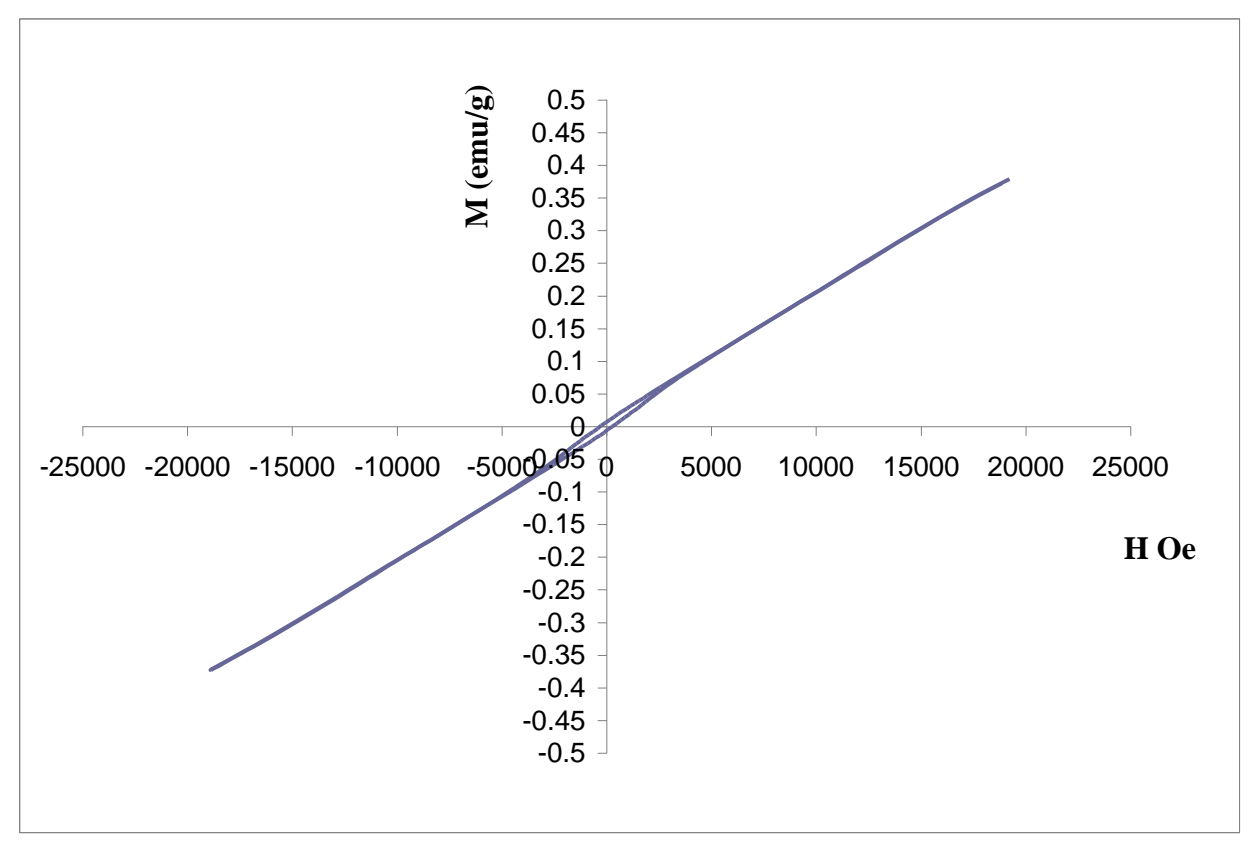

Fig.5. The hysteresis loop of the system under study.

Because of the broken exchange bonds and symmetry, a fraction of the total spins at the nano-particle surface will undergoes a non-collinear configuration with respect to the core ones. Consequently, the resultant 
magnetic moment observed is due to spin canting of $\mathrm{ZnFe}_{2} \mathrm{O}_{4}$ nano-particles. Moreover, the non-saturation of hysteresis loop at high magnetic field may be related to spin disorder in the surface of $\mathrm{ZnFe}_{2} \mathrm{O}_{4}$. The spin disorder at the surface may be related to spin canting and is explained by means of core-shell model $^{(35)}$. This model state that, with the increase in magnetic field simultaneous alignment of all the core moments along the applied field take place. As a result, the magnetization response is saturated. Further increase in the magnetic field will affect only the surface layer of particles and thus the rise in the magnetization slow down. The result is a virtual absence of magnetic saturation that keeps the hysteresis loops unsaturated even in very strong fields ${ }^{(20)}$. This charater is clearly identificed in Fig.5, where the absence of saturation even at the maximum applied field $(20 \mathrm{KOe})$ is detected. This behavior seems to be due to the surface spin disorder in nano regime in one part and because of magnetic moment bearing impurity phase $(\mathrm{ZnO})$ detected by XRD analysis given in Fig. 2 in the other part. Similar results concering the absence of the saturation regime have been also detected for nano crystalline $\mathrm{ZnFe}_{2} \mathrm{O}_{4}$ synthesized via different preparation technique ${ }^{(26,20,30)}$.

Figure 6 shows the change in magnetization of the system under study as a function of temperature at different applied magnetic fields (1010 Oe, 1340 Oe and 16600e). This figure shows that there is a gradual decrease in magnetization with temperature up to nearly $835 \mathrm{~K}$. It is assumed that the thermal energy helps the metal ions to overcome the energy barriers preventing an ordered cation distribution. Hence the inversion parameter decreases which results in the weakening of $\mathrm{A}-\mathrm{B}$ exchange interaction, therefore, there is a fall in the magnetization value. The Curie temperature of the material $\left(\mathrm{T}_{\mathrm{C}}\right)$ is nearly around $835 \mathrm{~K}$.

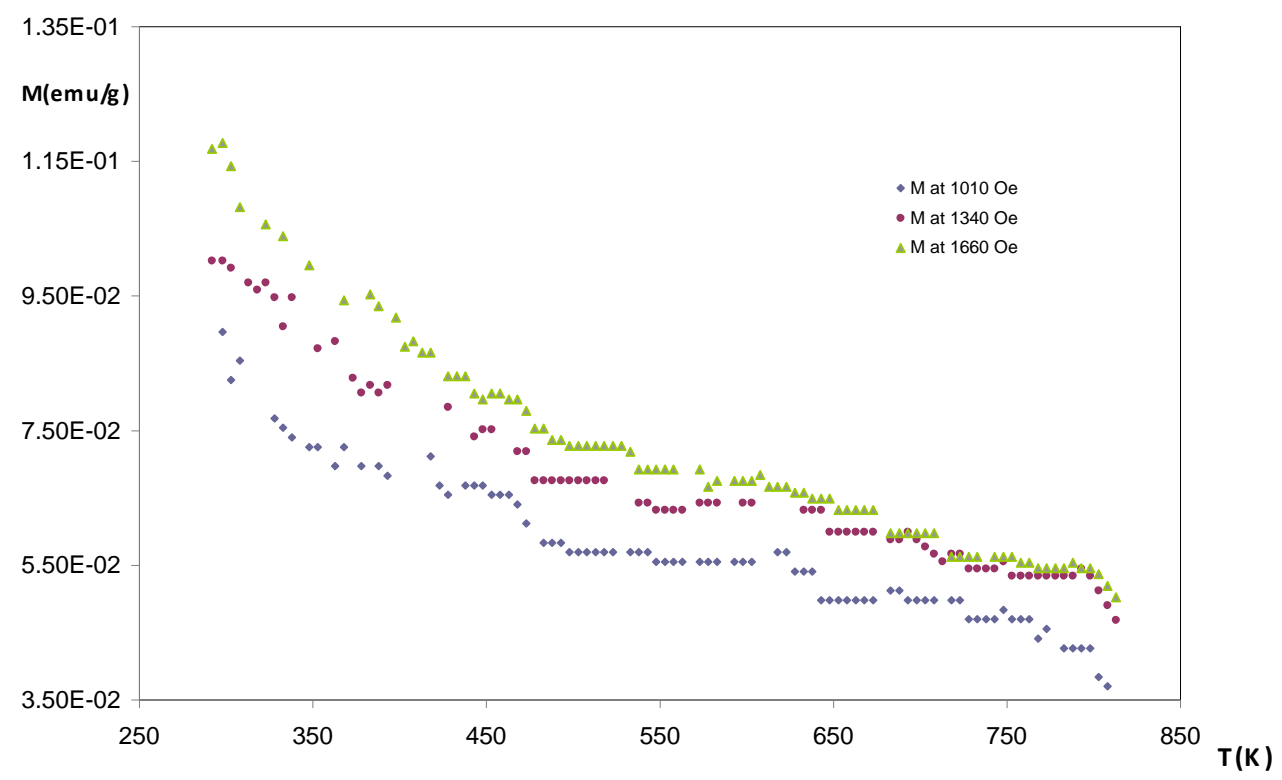

Fig.6. Plot of magnetization as a function of temperature at different applied magnetic fields of the system under study.

The calculated effective magnetic moments of the sample are 7.4751 B.M, 7.6553 B.M and 6.7975 B.M respectively at $1010 \mathrm{Oe}, 1340 \mathrm{Oe}$ and 1660 Oe (table 4).

Table 4. The $\mathrm{M}_{\mathrm{s}}(\mathrm{emu} / \mathrm{g}), \mathrm{M}_{\mathrm{r}}(\mathrm{emu} / \mathrm{g}), \mathrm{H}_{\mathrm{C}}(\mathrm{Oe}), \mu_{\mathrm{eff}}$ and $\mathrm{T}_{\mathrm{C}}\left(\mathrm{C}^{\circ}\right)$ calculated from magnetic measurements for the system under study. 


\begin{tabular}{|c|c|c|c|c|}
\hline $\mathrm{M}_{\mathrm{s}} \mathrm{emu} / \mathrm{g}$ & $\mathrm{M}_{\mathrm{r}} \mathrm{emu} / \mathrm{g}$ & $\mathrm{H}_{\mathrm{C}} \mathrm{Oe}$ & $\mu_{\text {eff }}$ at & $\mathrm{T}_{\mathrm{C}} \mathrm{K}$ \\
\hline & & & $10101340 \quad 166 \mathrm{Oe}$ & \\
\hline 0.37607 & 0.00676 & 289.2 & $7.475 \quad 7.655 \quad 6.797$ & 835 \\
\hline
\end{tabular}

There are widely scattered values of the Curie temperature of zinc ferrite in the literature. Deka and Joy ${ }^{(36)}$ have reported a $T_{\mathrm{c}}$ value equals to $800 \mathrm{~K}$ whereas Chen et al. ${ }^{(37)}$ reported a $T_{\mathrm{c}}$ value close to $600 \mathrm{~K}$ for thin film of zinc ferrite. It appears that the transition temperature of $\mathrm{ZnFe}_{2} \mathrm{O}_{4}$ may vary depending on sample processing and synthesis conditions, obviously on the nano size of the crystallites.

\section{Conclusion}

Preparation of nano-Zn ferrite sample was carried out by the direct fusion method. Investigation of structure and microstructure indicates the presence of two phases $66.66 \%$ and $33.33 \%$ respectively for the magnetic $\mathrm{ZnFe}_{2} \mathrm{O}_{4}$ and non-magnetic $\mathrm{ZnO}$ respectively. Lattice parameters, crystallite size and strain have be calculated. The ESR studies confirm that the defects are free spins with 2.00424 for the $g$ factor. The measured magnetic parameters suggests ferrimagnetic character of the system under study.

\section{References:}

1) N.M. Deraz, J. Anal. Appl. Pyrolysis, 10 (2011) 48

2) E.C. Snelling Soft Ferrites: Properties Applications ( $2^{\text {nd }}$ ed.) Butterworth Publishing, London (1989).

3) D.C. Jiles Introduction to Magnetism and Magnetic Materials ( $2^{\text {nd }}$ ed.)Chapman and Hall, London (1991).

4) M.A. Willard, L.K. Kurihara, E.E. Carpenter, S. Calvin, V.G. Harris Int. Mater. Rev., 49 (2004) 125.

5) O.S. Mathew, R.S. Jiang Chem. Eng. J., 129 (2007) 51.

6) B. Reddy, T. Sivasankar, M. Sivakumar, V. Moholkar Ultrason. Sonochem., 17 (2010) 416.

7) M. Anantharaman, S. Jagathesan, K. Malini, S. Sindhu, A. Narayanaswamy, C. Chinnasamy, J. Jacobs, S. Reijne, K. Seshan, R. Smits, H.J. Brongerma J. Magn. Magn. Mater., 189 (1998) 83.

8) J.F. Hochepied, P. Bonville, M.P. Pileni J. Phys. Chem. B, 104 (2000) 905 .

9) R. Skomski J. Phys. Condens. Matter., 15 (2003) R841.

10) O.M. Lemine, M. Bououdine, M. Sajieeddine, A.M. A-Saie, M. Shafi, A. Khatab, M. Al-hilai, M. henini. J. Physica B Condensed Matter, 406 (2011) 1989.

11) K. Tanaka, M. Makita, Y. Shimizugawa, K. Hirao, N. Soga J. Phys. Chem. Solids, 59 (9) (1998) 1611.

12) S. Bid, S.K. Pradhan Mater. Chem. Phys., 82 (1) (2003) 27.

13) X. Niu, W. Du, W. Du Sensors Actuators B, 99 (2-3) (2004) 405.

14) J.A. Toledo-Antonio, N. Nava, M. Mart'inez, X. Bokhimi Appl. Catal. A, 234 (1-2) (2002) 137.

15) J. Qiu, C. Wang, M. Gu Mater. Sci. Eng. B, 112 (1) (2004) 1.

16) M. Kobayashi, H. Shirai, M. Nunokawa Industrial and Eng. Chem. Res., 41 (12) (2002) 2903.

17) A. Verma, T.C. Goel, R.G. Mendiratta, M.I. Alam Mater. Sci. Eng. B, 60 (1999) 156.

18) B. Parvatheeswara Rao, P.S.V. Subba Rao, K.H. Rao IEEE Trans.

Magn., 33 (6) (1997) 4454.

19) P. Scardi, L. Lutterotti, and P. Masiterlli. Powder Diff., 9(3)

(1994) 180. 
20) A. Pradeep, P. Priyadharsin, G. Chandrasekaran, J. Alloys and Compounds, 509 (2011) 3917.

21) J.A. Toledo, M.A. Valenzuela, P. Bosch, H. Armendáriz, A. Montoya, N. Nava, A. Vazquez Appl. Catal. A: Gen., 198 (2000) 235.

22) I. Mohai, J. Szepvolgyi, I. Bertoti, M. Mohai, J. Gubicza, T. Ungar Solid State Ionics, 141/142 (2001) 163.

23) H. Yang, X. Zhang, C. Huang, W. Yang, G. Qiu J. Phys. Chem. Solids, 65 (2004) 1329.

24) W. Chen, L.F. Zhao, Y.Q. Wang, J.H. Miao, S. Liu, Z.C. Xia, S.L. Yuan Appl. Phys. Lett., 87 (2005) 042507.

25) G.L. Liu, Q. Cao, J.X. Deng, P.F. Xing, Y.F. Tian, Y.X. Chen, S.S. Yan, L.M. Mei Appl. Phys. Lett., 90 (2007) 052504.

26) M. Gacic, H. Adrian, G. Jakob Appl. Phys. Lett., 93 (2008) 152509.

27) B. Jeyadevan, B. Tohiji, K. Nakatsuka J. Appl. Phys., 76 (1994) 6325.

28) R.D.K. Misra, S. Gubbala, A. Kale, W.F. Egelhoff Jr. Mater. Sci. Eng. B, 111 (2004) 164.

29) F.K. Lotgering J. Phys. Chem. Solids, 27 (1966) 139.

30) M. mozaffari, M. Eghbali Arani, J.Magnetism and magnetic materials (2010).

31) C.N. Chinnasamy, A. Narayanasamy, N. Ponpandian, K. Chattopadhyay, H. Guérault, J.M. Greneche J. Phys.: Condens. Matter, 12 (2000) 7795.

32) C.N. Chinnasamy, A. Narayanasamy, N. Ponpandian, K. Chattopadhyay Mater. Sci. Eng. A, 304 (2001) 983.

33) Jun Wang, Chuan Zeng, Zhenmeng Peng, Qianwang Chen Physica B, 349 (2004) 124.

34) S.A. Oliver, H.H. Hamdeh, J.C. Ho Phys. Rev. B, 60 (1999) 3400.

35) R. H. Kodama, A. E. Berkowitz, E. J. McNiff, S. Foner. Phys. Rev. Lett., 77 (1996) 394.

36) S. Deka, P.A. Joy J. Nanosci. Nanotechnol., 8 (2008) 3955

37) Y.F. Chen, D. Spoddig, M. Ziese J. Phys. D: Appl. Phys., 41 (2008) 205004. 